\title{
A case of bilateral tubal ectopic pregnancy following intrauterine insemination
}

\author{
Efterpi Tingi ${ }^{1}$, Helena Misiura ${ }^{2}$, Mark Williams ${ }^{3}$, Sunday Ajayi ${ }^{1}$, Srisailesh Vitthala ${ }^{1}$ \\ 'Consultant in Obstetrics and Gynaecology, Furness General Hospital, Barrow-in- Furness \\ ${ }^{2}$ Specialty Registrar in Obstetrics and Gynaecology, Furness General Hospital, Barrow-in- Furness \\ ${ }^{3}$ Foundation year doctor Furness General Hospital, Barrow-in- Furness
}

Corresponding Author

Dr Efterpi Tingi, Consultant in Obstetrics and Gynaecology. e-mail: efterpi.tingi@doctors.org.uk

\section{Abstract}

The incidence of unilateral ectopic pregnancy (EP) is 1-2\% with the tubal EP being the commonest. Bilateral tubal pregnancy occurs 1 in every 750 to 1,850 EP following assisted reproductive technologies. We present a case of bilateral tubal EP in a 28 year old woman who underwent intrauterine insemination with donor sperm.

Key words: Bilateral tubal ectopic pregnancy, ntrauterine insemination

\section{Introduction}

The incidence of unilateral ectopic pregnancy (EP) is $1-2 \%$, with the tubal pregnancies being the commonest and accounting for $95 \%$ of all $\mathrm{EP}^{1}$. Bilateral tubal pregnancy (BTP) occurs more rarely in approximately 1 per 200,000 spontaneous pregnancies; however, this has increased to 1 in every 750 to 1,850 ectopic pregnancies ${ }^{2}$ following assisted reproductive technologies (ART).

We present a case of bilateral tubal EP in a 28 year old woman who underwent intrauterine insemination (IUI) with donor sperm.

\section{Case Report}

A 28-year-old healthy woman and her husband initially presented for infertility evaluation, which revealed normal ovarian reserve, unremarkable hysterosalpingogram (HSG) study and azoospermia of her male partner's semen analysis.

The couple opted for ovulation induction (OI) and IUI with donor sperm (IUI-D). The woman underwent OI with Letrozole $2.5 \mathrm{mg}$ twice daily from day 2 to day 6. Follicular monitoring was done by transvaginal ultrasonography (TV-USG) on alternate days from day 8. Two dominant follicles developed in the left ovary and none in the right ovary, these attained the sizes of 20 and $21 \mathrm{~mm}$ respectively.

She underwent IUI-D following 36 hour administration of 10,000-IU hCG trigger injections and TV-USG was suggestive of ovulation (both dominant follicles in the left ovary ruptured). Initial $\beta$-hCG 
test result was $541 \mathrm{mIU} / \mathrm{l}$ after two weeks of IUI-D and its level increased to $1171 \mathrm{mIU} / \mathrm{l}$ in 48 hours. One week later, TV-USG did not reveal intrauterine gestational sac despite doubling of $\beta$-hCG, which was $3648 \mathrm{mIU} / \mathrm{l}$ and it increased to $7492 \mathrm{mIU} / \mathrm{l}$ in 48 hours. TV-USG revealed left adnexal mass of 3-4 cms suggestive of an EP and a small amount of free fluid in the pouch of Douglas (POD).

Following discussion with the patient regarding tubal pregnancy and its implications, she agreed for laparoscopic left salpingectomy. The laparoscopic findings were around $3 \mathrm{~cm}$ discolored and distorted left ampullary tubal pregnancy impending to rupture, and unexpectedly the mid portion of right fallopian tube appeared dilated suggestive of concurrent unruptured second tubal pregnancy in the right fallopian tube. Left salpingectomy was essential given the abnormality of left fallopian tube with risk of impending rupture.

The available options with pros and cons were discussed with the patient's partner in detail following involvement of a fertility specialist. The decision was made for right salpingectomy after careful consideration, given the risk of recurrent right $\mathrm{EP}$ in the event of injection of methotrexate administration versus only chance of conception by ART (IVF/ ICSI -embryo transfer). Post-operative period was uneventful and histology confirmed bilateral tubal pregnancy.

The couple opted and consented for donor freeze thawed embryo transfer (D-FET). She underwent hormone replacement D-FET cycle with single blastocyst transfer. She conceived with singleton pregnancy. She had an uneventful antenatal period and delivered by elective caesarean section at 39 weeks for breech presentation.

\section{Discussion}

Spontaneous bilateral tubal EP is extremely rare and its incidence following IUI is estimated to be 1 in
1500 pregnancies $^{3}$. Obviously, the diagnosis of BTP could be difficult with the TV-USG alone ${ }^{4}$ and the vast majority of the cases reported in the literature were diagnosed late during diagnostic laparoscopy ${ }^{5,6}$. The $\beta$-hCG detection had no contribution to the diagnosis in our case even though it was doubling. The latter highlights the importance of the correlation between $\beta$-hCG and the absence of intrauterine gestational sac (IUGS) during TV-USG. Furthermore, BTP should be suspected in ART when a single adnexal mass is noted and the 48 hour $\beta$-hCG increases by more than $50 \%$ especially when more than one dominant follicle develops, even in the same side $e^{7,8}$.

The decision for the management of EP should be based on different factors which include the pregnancy location, the status of fallopian tube during the diagnosis and finally the consequences of the treatment onto future pregnancies ${ }^{3,9}$. The treatment of the BTP was challenging in our case as the patient had IUI for primary infertility. We faced an intraoperative dilemma regarding the management of the unruptured right EP. The available options were right salpingostomy, right salpingectomy or methotrexate (MTX) administration alone or with right salpingostomy. Occasionally, salpingostomy itself could be preferred to salpingectomy for fertility conservation; however this could lead to recurrence of EP as well as the continuity of trophoblastic disease in cases of molar pregnancy ${ }^{9}$. Bilateral salpingectomy is considered a good choice if the patient is counselled and willing for other ART such as ICSI or IVF-ET ${ }^{3}$.

A multidisciplinary approach for the treatment of unexpected contralateral EP is essential, as in most cases, due to the rarity - patients are not consented for bilateral salpingectomy. The patient's husband (power of attorney) was called in to the operative theatre and findings were shown. He was involved in all the decision-making process with regards to his wife's management plan. Another ethical dilemma was whether to re-operate at the later stage with 
patient's consent, however other issues were considered at the time including the unnecessary repeated surgical risk and delay in subsequent pregnancy.

In summary, bilateral tubal EP are rare and difficult to diagnose as there are not any specific diagnostic criteria, however its diagnosis should be considered in patients undergoing ART in view of the increased incidence compared to spontaneous conception. High degree of suspicion is important to diagnose BTP when $\beta$-hCG is doubling after reaching the threshold value and absence of IUGS ${ }^{10}$. The examination of both fallopian tubes during laparoscopy is essential if the diagnosis of bilateral tubal EP is made. A multidisciplinary approach should be taken to create an individualized treatment plan for each patient, taking into consideration future fertility.

\section{Conflicts of Interest}

The authors declare no conflicts of interest.

\section{References}

1. Xu H. A spontaneous bilateral tubal pregnancy: A case report. Medicine (Baltimore). 2018 Sep;97(38):e12365

2. Acet F, Goker ENT, Hortu I, Sahin G, Tavmergen E. A Rare Case of Bilateral Tubal Ectopic Pregnancy Following Intracytoplasmic Sperm Injection-Embryo Transfer (ICSI-ET). Rev Bras Ginecol Obstet. 2020 Mar;42(3):165-8.

3. Jamilian M. Bilateral tubal ectopic pregnancy following intra uterine insemination (IUI): A case re- port. Iran J Reprod Med. 2014 Feb;12(2):155-8.

4. Amine BH, Haythem S. Extra-uterine twin pregnancy: case report of spontaneous bilateral tubal ectopic pregnancy. Pan Afr Med J. 2015 Apr 30;20:435.

5. De Los Ríos JF, Castañeda JD, Miryam A. Bilateral ectopic pregnancy. J Minim Invasive Gynecol. 2007 Jul-Aug;14(4):419-27.

6. Hoffmann S, Abele H, Bachmann C. Spontaneous Bilateral Tubal Ectopic Pregnancy: Incidental Finding During Laparoscopy - Brief Report and Review of Literature. Geburtshilfe Frauenheilkd. 2016 Apr;76(4):413-6.

7. Funamizu A, Fukui A, Fukuhara R, Kobayashi A, Chiba H, Matsumura Y, Ito A, Mizunuma H. A case of bilateral tubal pregnancy. Gynecol Minim Invasive Ther. 2017 Oct-Dec;6(4):191-2.

8. Fukuda T, Inoue H, Toyama Y, Ichida T, Uzawa Y, Monma M, Kusaka T, Kohata Y. Bilateral tubal and intrauterine pregnancies diagnosed at laparoscopy. J Obstet Gynaecol Res. 2014 Oct;40(10):2114-7..

9. Zamané H, Yameogo B, Kain PD, Kaboré FGX, Sawadogo YA, Kiemtoré S, Kaboré SY, Thiéba BB. Bilateral Tubal Pregnancy without Known Risk Factor. Case Rep Obstet Gynecol. 2017;2017:4356036.

10. Edelstein MC, Morgan MA., Bilateral simultaneous tubal pregnancy: case report and review of the literature. Obstet Gynecol Surv. 1989 Apr;44(4):250-2.

Received 29-11-20

Revised 05-12-20

Accepted 10-12-20 